Check for updates

Cite this: RSC Adv., 2019, 9, 44

Received 30th September 2018 Accepted 4th December 2018

DOI: $10.1039 / c 8 r a 08137 a$

rsc.li/rsc-advances

\section{Preparation, structure identification and the anti- photoaging activity of peptide fraction OP-la from Ostrea rivularis}

\author{
Yuhui Ye, (D) ${ }^{\text {ab }}$ Lijun You, (D) *ab Qihui Deng, ${ }^{\text {ab }}$ Xiong Lia ${ }^{\text {ab }}$ and Mouming Zhao (D) ${ }^{\text {ab }}$
}

The purpose of the present study is to evaluate the preparation and the structure of fraction OP-la and its protective effect against UV-induced photoaging through the MAPKs signaling pathway. Fractions OP-la and OP-lb were prepared by enzymatic hydrolysis and purified by ultrafiltration (5 kDa) and gel chromatography (Sephadex G-25). The reducing power and superoxide radical scavenging ability were evaluated, which showed that OP-la had stronger antioxidant activity than OP-lb. Next, ten peptides were identified in OP-la by UPLC-MS/MS. The mechanism of the anti-photoaging activity for fraction OP-la was investigated through the MAPKs pathway based on the HaCaT cell line. Fraction OP-la could inhibit the generation of ROS and the decline of cell viability induced by UV radiation, meanwhile downregulate the expression of IL-1 $\beta, I L-8, c-J u n, c-F o s, p 65 \mathrm{NF}-\kappa B$ and p38 MAPK genes. Overall, the results showed that the fraction OP-la could be a potent component of functional foods with UV protection property.

\section{Introduction}

UV radiations are the high energy radiations in the sunlight spectrum. They are subdivided into UV-A (320-400 nm), UV-B $(280-320 \mathrm{~nm})$ and UV-C $(200-280 \mathrm{~nm}) .{ }^{1}$ Nowadays, the detrimental effect of UV light is increasing due to the depletion of the ozone layer. Excessive UV exposure can cause sunburn, tanning, photodermatoses, allergies, disfigurement, skin cancer, blindness, damage to immune system and even death. ${ }^{2}$ The latest data from the National Cancer Institute show that the new cases of melanoma of skin in US are increasing in the current years, ranking fifth among all cancers. Therefore, protection against UV-induced skin damage is gradually becoming a serious challenge for humans. Several natural compounds are found to act as antioxidants and antiinflammatory and immunomodulatory agents, which present potent anti-photoaging abilities. ${ }^{3,4}$ Exploring the possible mechanism behind their UV protective function may provide a novel and environmentally friendly alternative to fight against the harmful effects of UV radiation. Accumulated evidence shows the potential use of these bioactive compounds as protective natural products in cosmetics and functional foods. ${ }^{5}$ Peptides are important bioactive compounds that may possess strong anti-photoaging activity without side effects. Kim et al. ${ }^{6}$ found that low molecular weight peptides derived from donkey

${ }^{a}$ School of Food Science and Engineering, South China University of Technology, Guangzhou 510640, China. E-mail: feyoulijun@scut.edu.cn; Tel: +862087113848

${ }^{b}$ Overseas Expertise Introduction Center for Food Nutrition and Human Health (111 Center), Guangzhou 510640, China hide gelatin hydrolysates could protect human skin fibroblasts against UV-induced photoaging. Lu et al. ${ }^{7}$ isolated two peptides from cod skin gelatin hydrolysates and investigated their inhibitory effect through p-JNK in MAPK signalling pathways. Chen et $a .^{8}{ }^{8}$ investigated the protective effect of gelatin hydrolysate from salmon skin (SGH) on UV-induced photoaging of mice skin and found that SGH could inhibit the depletion of antioxidant defence components and enhance the synthesis of collagen and the function of immune system.

Ostrea rivularis is a type of shellfish largely distributed in the southern part of China, containing various nutrients like protein, taurine and functional micronutrients (Se, $\mathrm{Zn}, \mathrm{Ca}) .^{9}$ The major application of Ostrea rivularis is in the production of oyster sauce, which is universally used in Asian countries. ${ }^{10}$ However, the bioactive constituents in Ostrea rivularis are not fully investigated due to their product is not well developed, thus ignoring some potential functions inside. According to the available reports, only the polysaccharide in Ostrea rivularis has been well investigated. Li et al. ${ }^{11}$ evaluated the preparation method and the structural properties of the polysaccharide from Ostrea rivularis and its possible role in attenuating reproductive oxidative stress damage. So far, little literature has been seen on the anti-photoaging function of Ostrea rivularis peptides.

The purpose of the present study is to evaluate the preparation and the structure of a peptide fraction from Ostrea rivularis (OP-Ia) and its protective effect against UV-induced photoaging through the MAPKs (mitogen-activated protein kinases) signaling pathway. The results will pave the way for the development of functional foods with skin protection activities. 


\section{Material and methods}

\subsection{The preparation of peptide fraction OP-Ia}

Ostrea rivularis was obtained from Zhanjiang, Guangdong province, China. After cleaning, three times of water (water : substrate $=3: 1$ ) was added, and the mixture was homogenized. Then the homogenate was enzymatically hydrolyzed by Alcalase $2.4 \mathrm{~L}(\mathrm{pH}=$ $8.31, \mathrm{E} / \mathrm{S}=2 \%$, time for hydrolysis $=5.19 \mathrm{~h}$ ). The residue was centrifuged at $4500 \mathrm{rpm}$ for $15 \mathrm{~min}$ (Refrigerated benchtop centrifuge, Allegra X-15R, Beckman Coulter, IN, USA), to obtain the supernate. The crude Ostrea rivularis peptide was obtained after vaccum filtration and freeze drying (Freeze dryer, Alpha 1-2LD plus, Marin Christ, Osterode, Germany). The crude peptide was then purified by both ultrafiltration (Vivaflow 50R, Sartorius Ste$\operatorname{dim}$ Biotech, Germany), obtaining the fraction of $M_{\mathrm{w}}<5 \mathrm{kDa}$, and gel chromatography (Sephadex G-25, $1.6 \times 60 \mathrm{~cm}$, GE Healthcare, PA, USA), obtaining two fractions (OP-Ia \& OP-Ib). Then, their antioxidant activities were compared through reducing power and superoxide $\left(\mathrm{O}_{2}{ }^{-}\right)$radical scavenging ability, indicating that the antioxidant activity of OP-Ia was better than that of OP-Ib. Finally, OP-Ia was collected after freeze drying (Freeze dryer, Alpha 1-2LD plus, Marin Christ, Osterode, Germany).

\subsection{The reducing power of peptide fractions}

The estimation of the reducing power of peptide fractions was based on the method by Ahmadi, Kadivar and Shahedi ${ }^{\mathbf{1 2}}$ with slight modification. The samples $(2 \mathrm{~mL})$ were well mixed with $2 \mathrm{~mL}$ of $0.2 \mathrm{M}$ phosphate buffer ( $\mathrm{pH} 6.6$ ) and $2 \mathrm{~mL}$ of $1.0 \% \mathrm{~K}-$ ferricyanide. Then, the mixture was incubated at $50{ }^{\circ} \mathrm{C}$ in a water bath for $20 \mathrm{~min}$. Trichloroacetic acid $(10 \%, 2 \mathrm{~mL})$ was added to the mixture, and then centrifuged at $3000 \mathrm{rpm}$ for 10 min (Refrigerated benchtop centrifuge, Allegra X-15R, Beckman Coulter, IN, USA). The supernatant was collected (2 $\mathrm{mL}$ ), and then mixed with $2 \mathrm{~mL}$ of distilled water and $0.4 \mathrm{~mL}$ of $\mathrm{FeCl}_{3} \cdot 6 \mathrm{H}_{2} \mathrm{O}$. Next, the mixture was kept at room temperature $\left(28 \pm 2{ }^{\circ} \mathrm{C}\right)$ for $10 \mathrm{~min}$. Color changes were monitored at $700 \mathrm{~nm}$ by a spectrophotometer (Spectrophotometer, DU730, Beckman Coulter, IN, USA). The higher the absorbance, the better was the reducing power of the peptide fractions.

\subsection{The superoxide radical $\left(\mathrm{O}_{2}^{-}\right)$scavenging ability of peptide fractions}

The method for the estimation of superoxide radical scavenging ability of peptide fractions was based on Li et al. ${ }^{13}$ with slight modification. The peptide samples $(2 \mathrm{~mL})$ were dissolved in $4.5 \mathrm{~mL}$ of Tris-HCl buffer (0.1 M pH 8.2). Then, $0.5 \mathrm{~mL}$ of pyrogallol solution ( $3 \mathrm{mM}$ ) was added to it. The optical density (OD) was measured in triplicates at $325 \mathrm{~nm}$ using a spectrophotometer (Spectrophotometer, DU730, Beckman Coulter, IN, USA). The superoxide radical scavenging ability was calculated based on the change rate of OD.

\subsection{UPLC-MS/MS identification and sequence analysis}

The purified fraction OP-Ia was subjected to analytical RP-UPLC for peptide sequence analysis in an Agilent 1290 infinity machine using an SB-C18 column $(2.1 \times 50 \mathrm{~mm}$, RRHD $1.8 \mu \mathrm{m}$, Agilent, CA, USA). Five microliters of each peptide sample (1 mg $\mathrm{mL}^{-1}$ ) was loaded for each elution. The flow rate was 0.50 $\mathrm{mL} \min ^{-1}$. Mobile phase A was ultra-pure water and methanoic acid (1000: 1, v/v). Mobile phase B was acetonitrile. The elution program was set as 0-1 $\min , 0 \% \mathrm{~B}$; 1-9 $\mathrm{min}, 0-30.0 \% \mathrm{~B}$; 9$10 \mathrm{~min}, 30.0 \% \mathrm{~B} ; 10-13 \mathrm{~min}, 30.0-0 \% \mathrm{~B} ; 13-15 \mathrm{~min}, 0 \% \mathrm{~B}$. Column temperature was $30{ }^{\circ} \mathrm{C}$. The elution peaks were detected at the wavelength of $220 \mathrm{~nm}$ (TUV detector, Acquity UPLC, Waters, Ireland). The identification of the sequence was performed by electrospray ionization-quadrupole time-of-flight micromass spectrometer (ESI-Q-TOF-MS/MS). The data were acquired with a Bruker maxis impact ultra-high resolution mass spectrometer (Bruker Daltonics Inc., Billerica, MA, USA). The mass range was set at $80-1300 \mathrm{~m} / \mathrm{z}$ in positive ion modes. The quadrupole ion energy was set at $4.0 \mathrm{eV}$ while the collisioninduced dissociation energy was set at $8.0 \mathrm{eV}$. The parameters for the ESI interface were as follows: $180{ }^{\circ} \mathrm{C}$ drying gas temperature, 8.0 $\mathrm{L} \mathrm{min}{ }^{-1}$ drying gas flow and 1.5 bar ESI nebulizer pressure. The data of the sequence of peptide fraction OP-Ia were analyzed in UniProtKB.

\subsection{Cell culture and determination of cell viability}

The immortal keratinocyte cell line HaCaT (Jennio Biotech Co., Ltd, Guangzhou, China) was transferred to $25 \mathrm{~cm}^{2}$ culture flasks and grown in DMEM supplemented with $10 \%$ fetal bovine serum (FBS) and antibiotics $\left(100 \mathrm{U} \mathrm{mL}^{-1}\right.$ penicillin, $100 \mu \mathrm{g}$ $\mathrm{mL}^{-1}$ streptomycin). In addition, the cells were cultured in a humidified incubator with $5 \% \mathrm{CO}_{2}$ and $95 \%$ humidified air. The culture medium was changed every day.

When the HaCaT cells grew to $80-90 \%$ confluence, the cells were seeded in 96-well plates at a density of $1.7 \times 10^{4} /$ well. The cells were randomly divided into 8 groups: normal groups (normal cultured cells) treated with $0,500,1000$, and $1500 \mu \mathrm{mol}$ $\mathrm{L}^{-1}$ of OP-Ia, respectively. UV groups (UV-irradiated cells) treated with $0,500,1000$, and $1500 \mu \mathrm{mol} \mathrm{L}{ }^{-1}$ of OP-Ia, respectively. Specifically, the normal group (without OP-Ia) was defined as the control group. The UV group (without OP-Ia) was called the model group. After incubation for $12 \mathrm{~h}$, the cells were washed with PBS (Phosphate Buffer Saline), and then the culture medium was changed with serum-free DMEM medium and cultured for $12 \mathrm{~h}$. The cells were washed with PBS and covered with $100 \mu \mathrm{L}$ of PBS in each well. The UV radiation dose

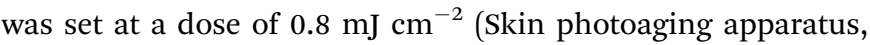
HOPE-MED 8140, Tianjin Hepu Industry \& Trade Co., Ltd., Tianjin, China). After UV treatment, the UV-irradiated cells were treated with different doses of OP-Ia in fresh serum-free DMEM $\left(0,500,1000\right.$, and $\left.1500 \mu \mathrm{mol} \mathrm{L}{ }^{-1}\right)$. The control groups followed the same procedure without UV irradiation. After incubation for $12 \mathrm{~h}$, the medium from each well was removed, and the cells were washed with PBS. Methylene blue $(50 \mu \mathrm{L})$ was added to each well, and incubated at $37^{\circ} \mathrm{C}$ for $1 \mathrm{~h}$. The plate was then rinsed by gently submerging in distilled water six times. Fifty microliters of elution buffer (50\% ethanol $+49 \%$ PBS $+1 \%$ acetic acid) was added into each well. Finally, the absorbance values were collected at $595 \mathrm{~nm}$ wavelength (SpectraMax 190, 
A

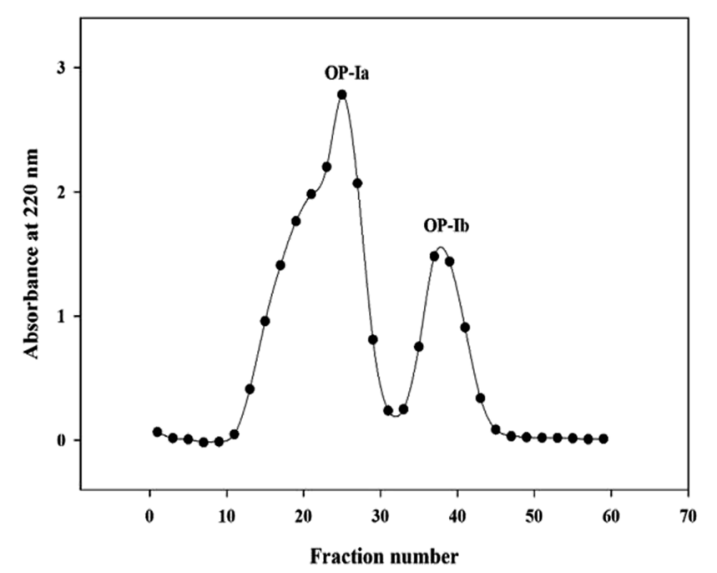

B

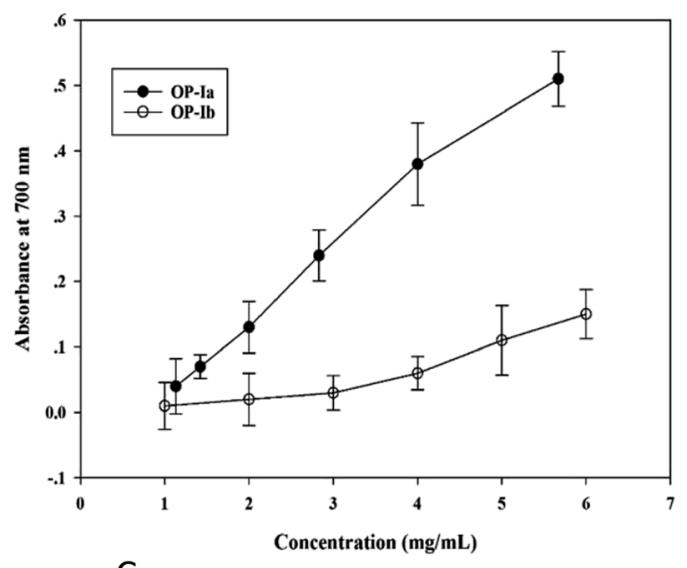

C

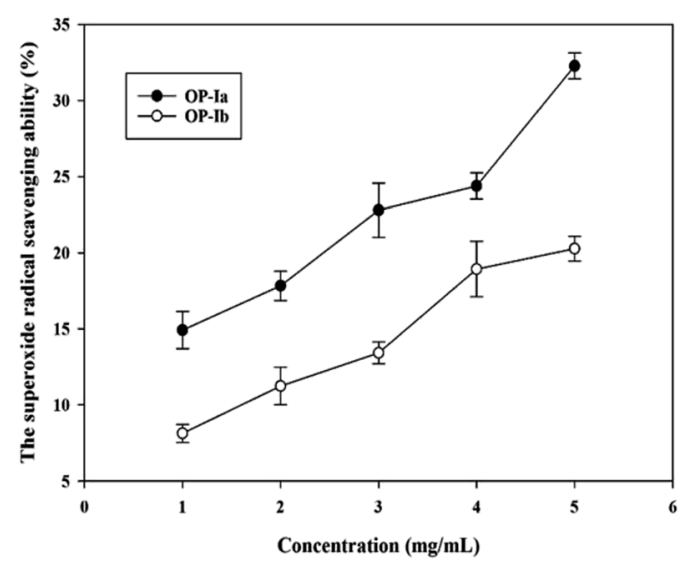

Fig. 1 The gel filtration chromatography of the crude peptide (A). The reducing power of peptide fractions ( $(B)$, mean $\pm S D, n=3)$. The superoxide radical $\left(\mathrm{O}_{2}^{-}\right)$scavenging ability of peptide fractions $((\mathrm{C})$, mean $\pm S D, n=3$ ).

Molecular Devices, CA, USA). Specifically, cells in the epidermal layer were stratified, which implies that their metabolism will differ from proliferating skin cells in culture to some extent, so it was indeed a limitation of the present study when using the HaCaT cell model to imitate the human epidermal layer.
Table 1 The main peptide sequence of OP-la ${ }^{a}$

\begin{tabular}{llrll}
\hline Number & $m / z$ & \multicolumn{1}{l}{$M_{\mathrm{w}}$} & Sequence & Source \\
\hline 1 & 318.16 & 634.29 & ISGSGTN & K1PRD5_CRAGI \\
2 & 332.17 & 662.31 & GNSLGLC & K1QCQ9_CRAGI \\
3 & 348.13 & 694.28 & CSMANAV & RIR1_OSHVF \\
4 & 351.15 & 700.31 & AGDDAPR & ACT_CRAGI \\
5 & 384.7 & 767.42 & EAPLNPK & ACT_CRAGI \\
6 & 274.13 & 819.41 & HVHNGRT & MAC1_CRANI \\
7 & 435.23 & 868.47 & TEAPLNPK & ACT_CRAVI \\
8 & 299.18 & 894.47 & HALRNVEG & MAC1_CRANI \\
9 & 543.33 & 1084.65 & GILGLSKLLGD & K1PI41_CRAGI \\
10 & 375.21 & 1122.59 & SYDDIKAAIK & E5CXX6_OSTED
\end{tabular}

${ }^{a}$ K1PRD5_CRAGI: trifunctional purine biosynthetic protein adenosine3. K1QCQ9_CRAGI: kynureninase. RIR1_OSHVF: ribonucleosidediphosphate reductase large subunit. ACT_CRAGI, ACT_CRAVI: actin. MAC1_CRANI: nacrein-like protein C1. K1PI41_CRAGI: flap endonuclease 1. E5CXX6_OSTED: glyceraldehyde-3-phosphate dehydrogenase.

\subsection{Determination of ROS (reactive oxygen species)}

The HaCaT cells were seeded in a 96-well flat-bottom plate and incubated for $24 \mathrm{~h}$. Then, the supernatant of each well was replaced by the same volume of different concentrations of OPIa. After incubation for $6 \mathrm{~h}, 100 \mu \mathrm{L}$ of DCFH-DA $(20 \mu \mathrm{M})$ in medium was added to each well and incubated for another $30 \mathrm{~min}$. The plate was washed with PBS three times to remove the residual and extracellular DCFH-DA, and then covered with PBS for the determination of fluorescence intensity using a fluorescence microplate reader (FilterMax F5, Molecular Devices, CA, USA) at $485 \mathrm{~nm}$ as the excitation wavelength and $535 \mathrm{~nm}$ as the emission wavelength.

\section{$2.7 \quad$ RT-qPCR analysis}

The expression of related genes in the MAPKs pathway was evaluated based on RT-qPCR analysis. Cells were seeded in 6-well flat-bottom plates at a concentration of $5 \times 10^{5}$ cells per $\mathrm{mL}$ followed by incubation for $24 \mathrm{~h}$. Then, the cells were incubated with OP-Ia at different concentrations for $24 \mathrm{~h}$, and later lysed for the extraction of total RNA using a total RNA isolation kit. ART reagent kit was used for erasing cDNA and reverse transcription of total RNA. Finally, the levels of cDNA encoding different targeted genes were measured using a real-time quantitative PCR instrument (Bio-Rad, CA, USA). GADPH (glyceraldehyde-3phosphate dehydrogenase) was applied as an internal reference. Real Time PCR Detection System was used under the following conditions: denaturation at $95{ }^{\circ} \mathrm{C}$ for $10 \mathrm{~s}$, followed by 40 cycles of $95{ }^{\circ} \mathrm{C}$ for $5 \mathrm{~s}, 60{ }^{\circ} \mathrm{C}$ for $30 \mathrm{~s}$ for amplification. The nucleotide sequences of primers used in RT-PCR were as follows: GAPDH (Gene ID: 2597) (forward, 5'-ACAGTCAGCCGCATCTTCTT-3'; reverse, 3'-AGGGGTCTACATGGCAACTG-5'); $c$ Fos (Gene ID: 2353) (forward, 5'-CTCGGGCTTCAACGCAGACTA3'; reverse, 3'-GGAATGAAGTTGGCACTGGAGAC-5'); c-Jun (Gene ID: 3725) (forward, $5^{\prime}$-AGAATCCGAAGGGAAAGGAA-3'; reverse, $3^{\prime}$ CTTCTCCTTCAGCAGGTTGG-5' ${ }^{\prime}$ ); $N F-K \beta$ (Gene ID: 4790) (forward, 5'-CAAAGTAGACCTGCCCAGAC-3'; reverse, 3'-GACCTCTCTCTAATCAGCCC-5'); $I L-8$ (Gene ID: 3576) (forward, $5^{\prime}-$ 
A

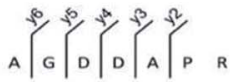

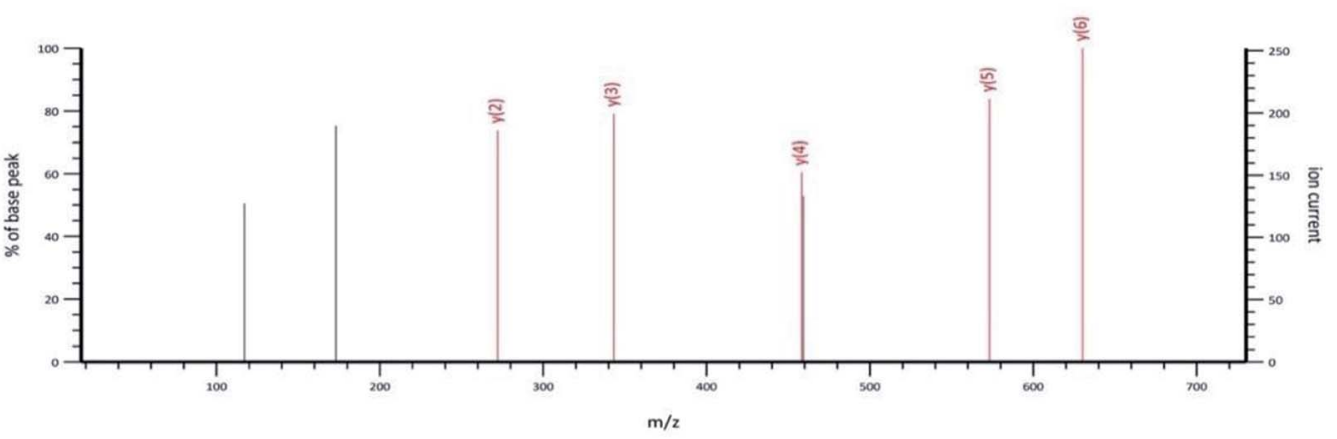

B

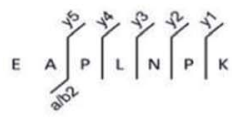

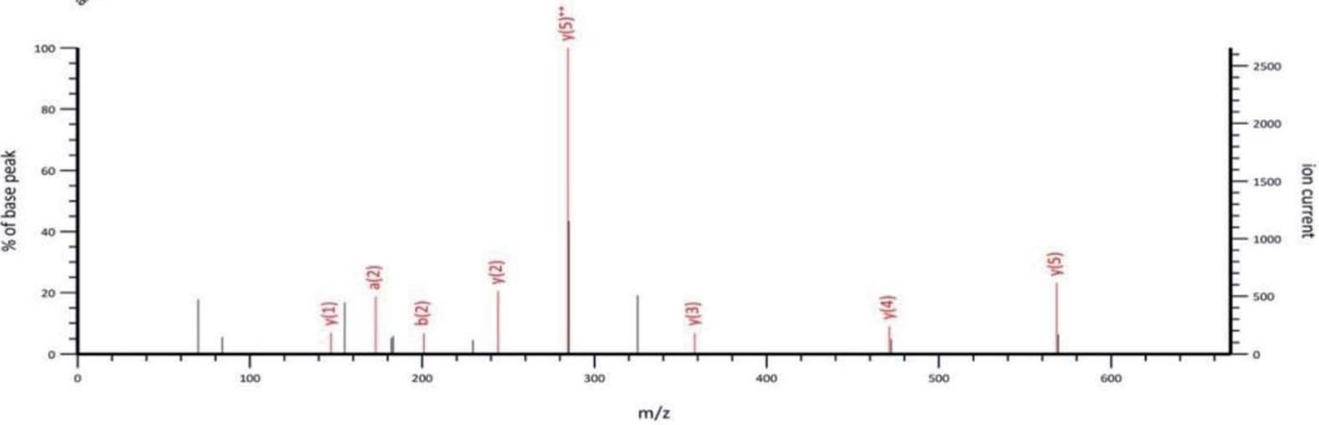

Fig. 2 The MS spectrum of the No. 4 peptide from OP-la (A). The MS spectrum of the No. 5 peptide from OP-la (B).

ATGATCTCCAAGCTGGGCCGTG-3'; reverse, $3^{\prime}$-TATGAATTCTCAGCCCTCTTCAAAA-5'); P38 (Gene ID: 5600) (forward, 5'TGTTGACCGGAAGAACGTTGT-3'; reverse, 3'-CAAAGTAGGCATGCGCAAGAG-5' ${ }^{\prime}$.

\subsection{Statistical analysis}

Data were presented as the mean \pm standard derivations (SDs) of three measurements. Analysis of significance was performed on SPSS 21 statistical software (SPSS Inc., Chicago, IL, USA) based on one-way ANOVA and Duncan's multiple comparison. $T$-test was carried out to compare the significant differences between samples and UV groups. $P$ values $<0.05$ were considered as statistically significant or extremely significant $(P$ values $<0.01)$.

\section{Result and discussion}

3.1 The preparation and the antioxidant activities of peptide fractions

The crude peptide was prepared from Ostrea rivularis by enzymatic hydrolysis. Then ultrafiltration $(5 \mathrm{kDa})$ and Sephadex G25 gel chromatography were conducted to purify the crude peptide, obtaining the purified fractions OP-Ia and OP-Ib (Fig. 1A).
Studies have reported that the generation of ROS, such as superoxide radicals, is largely related to photoaging and the antioxidant defense system. ${ }^{14}$ The reducing power indicates the ability to break the free radical chain by donating a hydrogen atom, while the superoxide radical scavenging ability defines the reducing activity of peptide fractions by an $\mathrm{O}_{2}{ }^{-}$-dependent reaction, which releases chromophoric products. Hence, in the present study, the two indexes were applied to compare the antioxidant activities of OP-Ia and OP-Ib, to screen the optimum fraction to carry out further research. Fig. 1B illustrates the reducing power of OP-Ia and OP-Ib. The reducing power of each fraction enhanced along with the increase in concentration, while the OP-Ia fraction possessed higher reducing power than the OP-Ib fraction (Fig. 1B). Similarly, Fig. 1C compares the superoxide radical scavenging ability of OP-Ia and OP-Ib. It shows that the superoxide radical scavenging ability of OP-Ia was higher than that of OP-Ib in the range of 1-5 $\mathrm{mg} \mathrm{mL}^{-1}$ (Fig. 1C). Therefore, OP-Ia was the optimum fraction that was appropriate to be further explored.

\subsection{The amino acid sequence of fraction OP-Ia}

The UPLC-MS/MS was harnessed to identify the structure of the OP-Ia fraction. As a result, ten peptides were identified: ISGSGTN (634.29 Da), GNSLGLC (662.31 Da), CSMANAV (694.28 


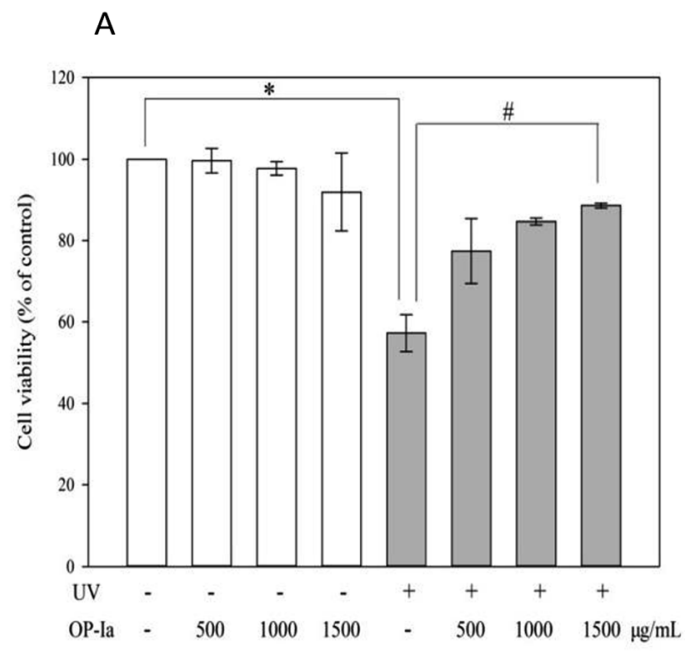

B

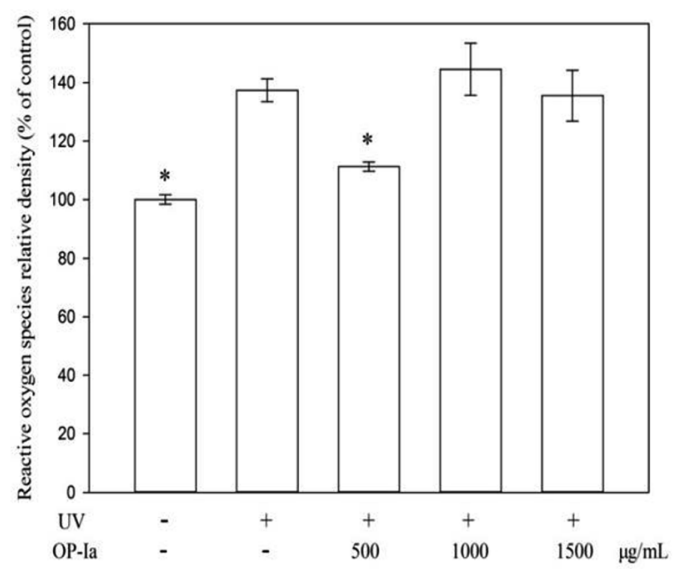

Fig. 3 Effect of OP-la on HaCaT cell viability and UV-induced phototoxicity (A). Effect of OP-la on intracellular ROS induced by UV radiation $(B)$. Bars marked with * represent the significance level between the model group and the control group $(P<0.05)$. Bars marked with \# represent the significance level between the model group and the UV groups $(P<0.05)$. (Mean $\pm \mathrm{SD}, n=3$ ).

Da), AGDDAPR (700.31 Da), EAPLNPK (767.42 Da), HVHNGRT (819.41 Da), TEAPLNPK (868.47 Da), HALRNVEG (894.47 Da), GILGLSKLLGD (1084.65 Da), SYDDIKAAIK (1122.59 Da) (Table 1). The typical MS spectrums of two heptapeptides (No. 4 \& No. 5) are shown in Fig. 2. The amino acid sequence of the No. 4 heptapeptide was AGDDAPR, and its mass to charge ratio and molecular weight were 351.15 and $700.31 \mathrm{Da}$, respectively. It came from the $23^{\text {rd }}$ to $29^{\text {th }}$ amino acids in protein ACT_CRAGI (Fig. 2A). The amino acid sequence of the No. 5 heptapeptide was EAPLNPK, and its mass to charge ratio and molecular weight were 384.70 and $767.42 \mathrm{Da}$, respectively. It came from the $108^{\text {th }}$ to $114^{\text {th }}$ amino acids in protein ACT_CRAGI (Fig. 2B).

\subsection{Effect of fraction OP-Ia on HaCaT cell viability and UV- induced phototoxicity}

The anti-photoaging activity of fraction OP-Ia was evaluated based on the HaCaT cell line. HaCaT is a spontaneously transformed aneuploid immortal keratinocyte cell line from adult human skin. It serves as the main content of the human epidermis, which takes up more than $95 \%$. During its continuous differentiation, the cell size, shape and arrangement can undergo regular changes, which ultimately lead to the formation of keratin-rich stratum corneum. This creates a protective layer that isolates the inner layers from bacteria, fungi, parasites, viruses, overheated environments and ultraviolet radiation. ${ }^{15}$ Therefore, it is widely used as a stable anti-radiation cell model. Compared to the normal epidermal cell, HaCaT has almost the same behavior and stronger cell viability that makes it feasible to be used in the present study. Firstly, the safe criteria of the dose of OP-Ia were tested and the UV-induced phototoxicity was revealed. Fig. 3A indicates that none of the doses of OP-Ia $\left(0-1500 \mu \mathrm{g} \mathrm{mL}^{-1}\right)$ had cytotoxic effect on HaCaT cells (death rate $<10 \%$ ). After UV treatment, the cell viability significantly dropped to $57.3 \%$ of control $(P<0.05)$. Then it increased after OP-Ia treatment in a nice dose-dependent manner. At the dose of $1500 \mu \mathrm{g} \mathrm{mL} \mathrm{m}^{-1}$, it reached up to $88.6 \%$. In the current model, the cell viability was about $50 \%$ of the control caused by UV radiation, in order to make sure that the photoaging-related genes were induced while the HaCaT cells were still partly active. Similarly, Cha et al. ${ }^{16}$ found that when the cell viability was around $50 \%$ of the control, it indicated that the cell did not reduce considerably whereas the protein expression was induced. Therefore, we concluded that the UVinduced phototoxicity model was built successfully based on HaCaT cell viability. Also, OP-Ia fraction $\left(0-1500 \mu \mathrm{g} \mathrm{mL} \mathrm{m}^{-1}\right)$ could significantly increase the cell viability after UV irradiation $(P<$ 0.05 ) and have no cytotoxic effect on the HaCaT cells.

\subsection{Effect of fraction OP-Ia on intracellular ROS induced by UV}

Excessive ROS was the inducer of oxidative stress in cells. However, UV radiation could trigger ROS generation. When the antioxidant capacity of cells is not strong enough to remove the excessive ROS, oxidative stress occurs, which finally leads to photoaging. ${ }^{17}$ Fig. $3 \mathrm{~B}$ shows that UV irradiation can significantly increase the level of ROS in HaCaT cells $(P<0.05)$, while $500 \mu \mathrm{g}$ $\mathrm{mL}^{-1}$ of fraction OP-Ia can significantly attenuate the generation of intracellular ROS compared to the model group $(P<$ $0.05)$.

\subsection{Effect of fraction OP-Ia on expression of photoaging- related gene}

3.5.1 Effect of fraction OP-Ia on IL-1 $\beta$ and IL-8 mRNA expression. UV radiation could cause severe inflammation of skin and generate various cytokines in both epidermis and dermis. There were two pathways: these cytokines mainly acted through stimulating NF- $\kappa B$ (nuclear factor- $\kappa B$ ) levels in the cytoplasm or stimulating MAPK levels in the cell. ${ }^{18} \mathrm{IL}-1 \beta$ and IL8 were the typical inflammatory factors in the photoaging process. Jin et al. ${ }^{19}$ found that both mRNA and protein levels of IL-1 $\beta$ were increased drastically by UV, which could cause skin thickening and inflammation. IL-8 took part in the formation of cutaneous melanoma, and UV was responsible for the initiation 

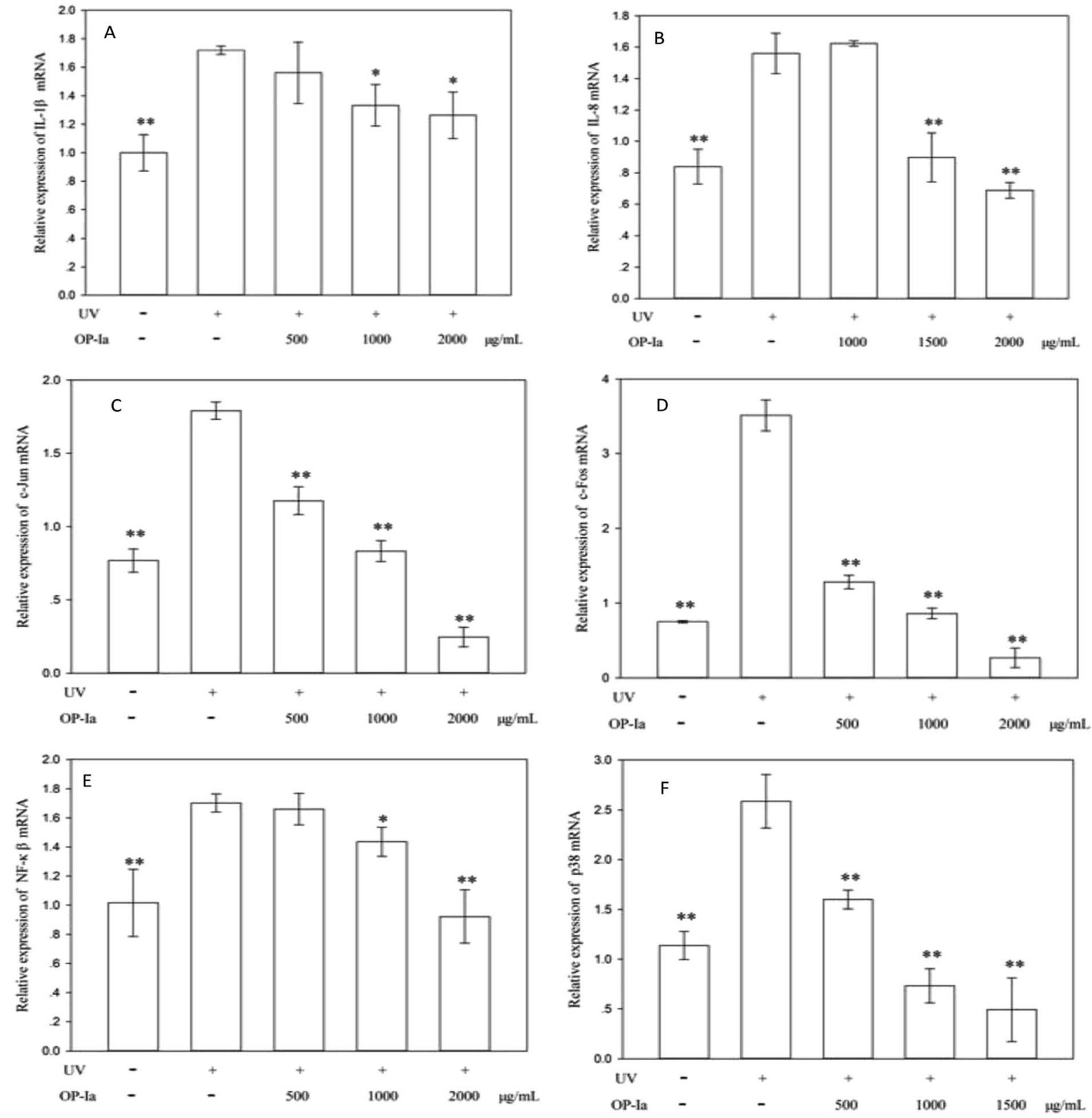

Fig. 4 Effect of OP-la on IL-1 $\beta$ (A), IL-8(B), c-Jun (C), c-Fos (D), p65 NF- $\kappa B$ (E) and p38 MAPK (F) mRNA expression. Bars marked with * and ** represent the significance level between the model group and the control group $(P<0.05$ and $P<0.01$, respectively). (Mean $\pm \mathrm{SD}, n=3$ ).

of melanoma via induction of autocrine IL-8. ${ }^{20}$ Fig. $4 \mathrm{~A}$ and $\mathrm{B}$ illustrate that the expression of IL- $1 \beta$ and IL-8 upregulated significantly (1.72-fold of control) due to the effect of UV radiation. Fraction OP-Ia at 1000 and $1500 \mu \mathrm{g} \mathrm{mL}{ }^{-1}$ could downregulate the IL-1 $\beta$ expression to 1.33-fold and 1.26-fold of control, respectively, compared to those of the model group.

3.5.2 Effect of fraction OP-Ia on c-Jun and c-Fos mRNA expression. Many transcription factors played significant roles in the photoaging process. For example, activator protein-1 (AP1), which consisted of c-Jun and c-Fos, was a critical mediator in a number of cellular processes including differentiation, proliferation, and apoptosis. Xiao et al. ${ }^{21}$ found that AP-1 played a crucial role in the initiation of apoptotic nerve cell death.
Moreover, c-Jun and c-Fos served as the early apoptotic genes, which were upregulated by Synsepalum dulcificum extracts in the human colorectal cancer cells. ${ }^{22}$ UV radiation was reported to induce the binding between c-Jun and c-Fos, thus leading to photodamage. Park et al. ${ }^{23}$ indicated that UV radiation caused an increase in the expression and activation of both c-Jun and cFos by $154 \%$ and $166 \%$, respectively. Fig. 4C and D illustrate that UV radiation activated the expression of both c-Jun and cFos significantly (2.32-fold and 4.20-fold of control, respectively, $P<0.01)$, while different doses of OP-Ia $(500,1000$, and $2000 \mu \mathrm{g} \mathrm{mL}^{-1}$ ) could downregulate their expression.

3.5.3 Effect of fraction OP-Ia on p65 NF- $\mathrm{B}$ and p38 MAPK mRNA expression. NF- $\kappa \mathrm{B}$ family is one of the most essential 


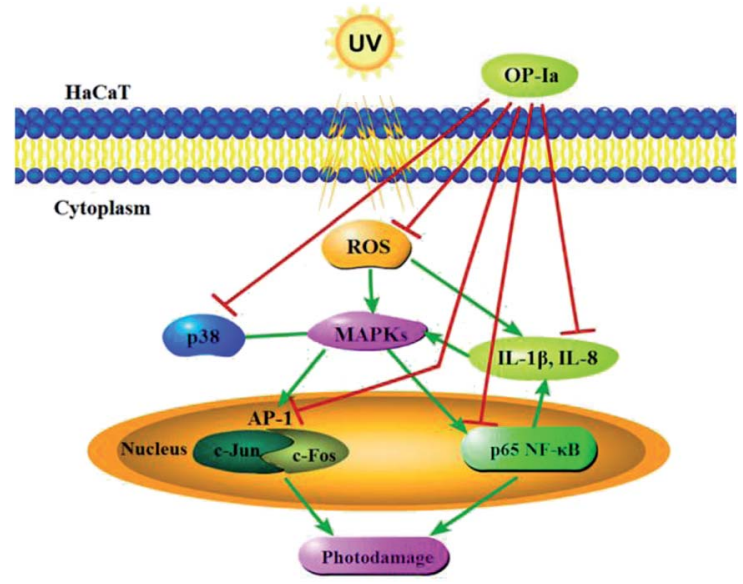

Fig. 5 The possible involved pathway of the anti-photoaging effect of OP-la.

transcription factors in the cell nucleus. P65 is a subunit of NF$\kappa \mathrm{B}$ family, which plays important roles in cell inflammation and apoptosis. Zhou et al. $^{24}$ found that resveratrol could downregulate p65 expression and protect HaCaT from UVB-induced photoaging. Fig. $4 \mathrm{E}$ shows that $\mathrm{UV}$ radiation induced the upregulation of p65 NF- $\kappa \mathrm{B}$ gene significantly to 1.68-fold of the control $(P<0.01)$, whereas 1000 and $2000 \mu \mathrm{g} \mathrm{mL} \mathrm{mL}^{-1}$ of OP-Ia inhibited its expression significantly to 1.43 -fold $(P<0.05)$ and 0.91 -fold $(P<0.01)$ of the control, respectively.

P38 is a class of MAPKs, which involves in cell differentiation, apoptosis and autophagy after ultraviolet radiation inducement. Many reports indicate that p38 MAPK is the pivot gene in the photoaging process. Han et al. ${ }^{25}$ revealed that black rice extracts attenuated UV-induced extracellular damage by modulating the p38 MAPK pathway and AP-1 signaling. Similarly, Kong et al. ${ }^{26}$ investigated the protective effect of paeoniflorin against UVB-induced apoptosis in human keratinocytes, and found that the ROS-p38-p53 pathway was activated due to the UV radiation. Fig. $4 \mathrm{~F}$ shows that the expression of p38 MAPK was upregulated to 2.27-fold of control induced by UV radiation $(P<0.01)$, whereas all doses of OP-Ia could suppress its expression significantly $(P<0.01)$.

The above results evaluated the anti-photoaging activity of fraction OP-Ia based on the MAPKs signal pathway. The possible pathway involved in this study is illustrated in Fig. 5. ROS was generated due to the stimuli of UV radiation and then led to MAPKs (including p38, ERK, JNK) activation. The upregulation of MAPKs could transfer c-Jun and c-Fos to the nucleus and induce the activation of $\mathrm{NF} \kappa \mathrm{B}$, which subsequently induced the upregulation of the expression of IL-1 $\beta$ and IL-8. ${ }^{27-29}$ All these factors could lead to photodamage, whereas fraction OPIa inhibited the expression of the related genes in the MAPKs signaling pathway, displaying a potent anti-photoaging activity in HaCaT cells.

\section{Conclusion}

The present study investigated the preparation and the structure of the fraction OP-Ia and the possible mechanism for its protective activity against UV-induced photodamage in HaCaT cell. Ten peptides were identified by UPLC-MS/MS: ISGSGTN (634.29 Da), GNSLGLC (662.31 Da), CSMANAV (694.28 Da), AGDDAPR (700.31 Da), EAPLNPK (767.42 Da), HVHNGRT (819.41 Da), TEAPLNPK (868.47 Da), HALRNVEG (894.47 Da), GILGLSKLLGD (1084.65 Da), SYDDIKAAIK (1122.59 Da). The possible mechanism of the anti-photoaging activity of fraction OP-Ia was explored through the MAPKs pathway. Fraction OP-Ia could inhibit the generation of ROS and the decline of cell viability induced by UV radiation, meanwhile downregulate the expression of IL-1 $\beta$, IL-8, c-Jun, c-Fos, p65 NF- $\kappa$ B and p38 MAPK genes in HaCaT cell. Therefore, fraction OP-Ia could protect human skin keratinocyte against photoaging damage, making it possible to be harnessed in functional foods with skin protection activity.

\section{Conflicts of interest}

There are no conflicts to declare.

\section{Acknowledgements}

This study was funded by Guangdong Special Support Program (2015TQ01N670), Pearl River S\&T Nova Program of Guangzhou (201610010096), the National Natural Science Foundation of Guangdong Province (2016A030312001) and the 111 Project (B17018).

\section{References}

1 A. Nazir, M. A. Saleem, F. Nazir, T. Hussain, M. Q. Faizan and M. Usman, Photochem. Photobiol., 2016, 92, 343-347.

2 Y. Ye, D. Sun-Waterhouse, L. You and A. M. Abbasi, Int. J. Food Sci. Technol., 2017, 52, 595-607.

3 N. Saewan and A. Jimtaisong, J. Cosmet. Dermatol., 2015, 14, 47-63.

4 Y. Ye, D. Ji, L. You, L. Zhou, Z. Zhao and C. Brennan, J. Funct. Foods, 2018, 43, 8-16.

5 A. A. Farooqi, R. N. Li, H. W. Huang, M. Ismail, S. S. F Yuan, H. M. D Wang, J. R. Liu, J. Y. Tang and H. W. Chang, Curr. Pharm. Biotechnol., 2015, 16, 1078-1084.

6 J. S. Kim, D. Kim, H. J. Kim and A. Jang, Process Biochem., 2018, 67, 118-126.

7 J. Lu, H. Hou, Y. Fan, T. Yang and B. Li, J. Funct. Foods, 2017, 33, 251-260.

8 T. Chen, H. Hou, J. Lu, K. Zhang and B. Li, J. Ocean Univ. China, 2016, 15, 711-718.

9 Y. Liu, C. Zhang and S. Chen, Food Sci. Technol. Res., 2013, 19, 417-424.

10 J. Y. Je, P. J. Park, W. K. Jung and S. K. Kim, Food Chem., 2005, 91, 15-18.

11 S. Li, Z. Song, T. Liu, J. Liang, J. Yuan, Z. Xu, Z. Sun, X. Lai, Q. Xiong and D. Zhang, Carbohydr. Polym., 2018, 186, 321331.

12 F. Ahmadi, M. Kadivar and M. Shahedi, Food Chem., 2007, 105, 57-64. 
13 Y. Li, B. Jiang, T. Zhang, W. Mu and J. Liu, Food Chem., 2008, 106, 444-450.

14 B. Ryu, Z. J. Qian, M. M. Kim, K. W. Nam and S. K. Kim, Radiat. Phys. Chem., 2009, 78, 98-105.

15 D. Ji, L. You, Y. Ren, L. Wen, G. Zheng and C. Li, J. Funct. Foods, 2017, 36, 332-340.

16 J. W. Cha, M. J. Piao, K. C. Kim, C. W. Yao, J. Zheng, S. M. Kim, C. L. Hyun, Y. S. Ahn and J. W. Hyun, Biomol. Ther., 2014, 22, 136.

17 J. M. Rijnkels, R. M. W. Moison and E. Podda, Radiat. Res., 2003, 159, 210.

18 H. Shah and S. R. Mahajan, Biomed. Aging Pathol., 2013, 3, 161-169.

19 X. J. Jin, E. J. Kim, I. K. Oh, Y. K. Kim, C. H. Park and J. H. Chung, J. Korean Med. Sci., 2010, 25, 930.

20 C. Gebhardt, M. Averbeck, A. Viertel, F. Kauer, A. Saalbach, U. Anderegg and J. C. Simon, Exp. Dermatol., 2007, 16, 636-643.
21 P. Xiao, X. Liu, N. Zhao, R. Fang, Q. Wen, K. Zeng and Y. Wang, Eur. Rev. Med. Pharmacol. Sci., 2018, 22, 2832-2838.

22 J. Seong, G. G. Oyong and E. C. Cabrera, Asian Pac. J. Trop. Biomed., 2018, 8, 173.

23 B. Park, E. Hwang, S. A. Seo, M. Zhang, S. Y. Park and T. H. Yi, J. Funct. Foods, 2017, 36, 480-489.

24 F. Zhou, X. Huang, Y. Pan, D. Cao, C. Liu, Y. Liu and A. Chen, Biochem. Biophys. Res. Commun., 2018, 499, 662-668.

25 M. Han, J. S. Bae, J. J. Ban, H. S. Shin, D. H. Lee and J. H. Chung, Int. J. Mol. Med., 2018, 41, 3073-3080.

26 L. Kong, S. Wang, X. Wu, F. Zuo, H. Qin and J. Wu, Mol. Med. Rep., 2016, 13, 3553-3558.

27 D. R. Bickers and M. Athar, J. Invest. Dermatol., 2006, 126, 2565-2575.

28 Y. W. Su, W. F. Chiou, S. H. Chao, M. H. Lee, C. C. Chen and Y. C. Tsai, Int. Immunopharmacol., 2011, 11, 1166-1172.

29 X. Chen, S. A. Tang, E. Lee, Y. Qiu, R. Wang, H. Q. Duan, S. Dan, M. Jin and D. Kong, Life Sci., 2015, 124, 8-15. 